Nutrition Research Reviews (2019), 32, 176-182

(C) The Authors 2019. This is an Open Access article, distributed under the terms of the Creative Commons AttributionNonCommercial-ShareAlike licence (http://creativecommons.org/licenses/by-nc-sa/4.0/), which permits non-commercial re-use, distribution, and reproduction in any medium, provided the same Creative Commons licence is included and the original work is properly cited. The written permission of Cambridge University Press must be obtained for commercial re-use.

\title{
Gut rest strategy and trophic feeding in the acute phase of critical illness with acute gastrointestinal injury
}

\author{
Dong Zhang, Hongxiang Li* (1), Yuting Li and Lai Qu \\ Intensive Care Unit, First Hospital of Jilin University, 71 Xinmin Street, Changchun, People's Republic of China
}

\begin{abstract}
Critically ill patients frequently suffer from gastrointestinal dysfunction as the intestine is a vulnerable organ. In critically ill patients who require nutritional support, the current guidelines recommend the use of enteral nutrition within $24-48 \mathrm{~h}$ and advancing towards optimal nutritional goals over the next 48-72 h; however, this may be contraindicated in patients with acute gastrointestinal injury because overuse of the gut in the acute phase of critical illness may have an adverse effect on the prognosis. We propose that trophic feeding after $72 \mathrm{~h}$, as a partial gut rest strategy, should be provided to critically ill patients during the acute phase of illness as an organ-protective strategy, especially for those with acute gastrointestinal injury.
\end{abstract}

Key words: Acute gastrointestinal injury: Enteral nutrition: Trophic feeding: Gut rest strategy

\section{Introduction}

In critically ill patients, the intestine is susceptible to injury, and gastrointestinal (GI) injury is common ${ }^{(1)}$. Evidence suggests that an estimated $50 \%$ of patients have enterocyte damage at admission to the intensive care unit (ICU), and GI symptoms occur in approximately $62 \%$ of patients in the $\mathrm{ICU}^{(2)}$. The Working Group on Abdominal Problems (WGAP) of the European Society of Intensive Care Medicine (ESICM) proposed a set of definitions and grading system for GI dysfunction. They defined acute GI injury (AGI) as malfunctioning of the GI tract in critically ill patients due to their acute illness ${ }^{(3)}$. Studies have shown that critically ill patients with AGI experience higher mortality rates as compared with patients without $\mathrm{AGI}^{(4-6)}$

As one of the GI tract functions is to ingest, digest and absorb nutrients from food and water, AGI can manifest as feeding intolerance (defined as intolerance to enteral nutrition (EN) wherein intake of $\geq 20 \mathrm{kcal}(\geq 84 \mathrm{~kJ}) / \mathrm{kg}$ body weight per $\mathrm{d}$ cannot be achieved within $72 \mathrm{~h}$ of feeding attempts via the enteral route $)^{(3)}$. However, clinical practice guidelines of the ESICM recommend initiation of early EN (EEN) within 24-48 h of ICU admission, advancing towards optimal nutritional goals over the next 48 $72 \mathrm{~h}^{(7)}$. Therefore, some questions remain regarding the use of nutritional support in critically ill patients: (1) Is EN safe in critically ill patients with AGI? (2) Will these patients benefit from using the injured organ? (3) Does the GI tract of critically ill patients require 'rest' for the recovery of GI function? The present review seeks to explore answers to these questions based on the contemporary body of evidence.

\section{Gastrointestinal dysfunction in the acute phase of critical} illness

The acute phase of critical illness lasts for at least $7 \mathrm{~d}^{(8)}$, and has been variously defined in clinical trials as the first few days after onset of illness, or the first 5-7 d after admission to the $\operatorname{ICU}^{(9-11)}$. The acute phase is usually caused by injury (shock, trauma or infection $)^{(8)}$, which imposes stress on the body due to compensatory pathophysiological changes in an attempt to restore stability within the internal environment ${ }^{(12)}$. The adaptive response to acute critical illness includes the metabolic response to stress ${ }^{(13)}$, which involves neuroendocrine, inflammatory and immune mechanisms that cause rapid catabolism and induce resistance to anabolic signals, including insulin. This prioritises the delivery of glucose to organs that cannot use other substrates as energy $^{(14,15)}$. These adaptive changes are complex and sequential and have largely been a barrier to the successful development of targeted interventions to modulate the metabolic response to critical illness ${ }^{(15)}$.

In addition, excessive or inadequate adaptive responses evoked by intensive stress ${ }^{(12)}$ can have an impact on the GI tract, including negative effect on gut motility ${ }^{(16,17)}$, mucosal blood flow $^{(18)}$ and increased mucosal permeability ${ }^{(19)}$ through neuroendocrine regulation ${ }^{(20)}$. In particular, the adaptive response to acute stress also includes an adrenergic response with the consequent increase in catecholamine levels which may cause constriction of GI vessels and decrease intestinal blood flow ${ }^{(21)}$. In addition to endogenous regulation, exogenous catecholamines administered to treat shock may also divert blood flow away

Abbreviations: AGI, acute gastrointestinal injury; ALI, acute lung injury; AP, acute pancreatitis; ASPEN, American Society for Parenteral and Enteral Nutrition; EEN, early enteral nutrition; EN, enteral nutrition; ESICM, European Society of Intensive Care Medicine; GI, gastrointestinal; ICU, intensive care unit; MV, mechanical ventilation; PN, parenteral nutrition; RCT, randomised controlled trial; SCCM, Society of Critical Care Medicine; WGAP, Working Group on Abdominal Problems.

* Corresponding author: Hongxiang Li, email yaloos@sina.com 
from the mesenteric circulation and decrease microvascular perfusion in the gut ${ }^{(22)}$. GI blood flow is reduced in some critically ill patients despite treatment with fluid replacement and interventions to normalise blood pressure and cardiac function ${ }^{(23)}$. Moreover, intense vasoconstriction and hypoperfusion of the intestines have been shown to persist during early sepsis even in patients with normal blood pressure ${ }^{(24)}$. Decreased GI blood flow induces up-regulation of apoptosis and decreases proliferation of small bowel mucosal cells, which leads to thinning of the gut mucosa and decrease in absorptive surface of the small bowel ${ }^{(25)}$. With continued disease progression, tissue oedema, endothelial injury ${ }^{(26)}$ and capillary leaking occur in the gut ${ }^{(27)}$. These injuries result in improper digestion and absorption ${ }^{(3)}$, impairment of the intestinal barrier ${ }^{(28)}$ and dysregulation of the intestinal microbiota ${ }^{(29)}$.

The symptom profile of improper digestion and absorption is characterised by temporary self-limiting GI symptoms, which progress to the feeding intolerance syndrome as GI dysfunction becomes more severe ${ }^{(1,3)}$. Small-intestinal mucosal integrity may also be compromised in critically ill patients, leading to increased intestinal permeability, especially in patients intolerant to $\mathrm{EN}^{(30)}$. Furthermore, critical illness alters the gut microbiota; the gut microbiota of critically ill patients is characterised by low diversity, low abundance of key commensal genera and overgrowth of a single bacterial genus ${ }^{(29)}$ (Fig. 1). Dysbiosis of the gut microbiota may result in organ dysfunction ${ }^{(31)}$, and should be part of the evaluation of GI function in the future. The gut microbiome has large potential as a future therapeutic or diagnostic target. However, current evidence on microbiota-targeted therapies in critical illness remains unclear ${ }^{(31)}$.

The ESICM WGAP classification of AGI in critical illness is mainly based on the degree of impairment of digestion and absorption functions ${ }^{(3,27)}$. AGI grade I refers to development of new GI symptoms (such as vomiting, gastric residual volume, diarrhoea, GI bleeding, paralysis of lower GI tract, or abnormal bowel sounds), which are related to a known cause and perceived as transient (risk of developing GI dysfunction or failure). Lack of improvement in these symptoms and no changes in the general condition are graded as AGI grade II (GI dysfunction). AGI grade II is an indication for intervention (for example, prokinetics, postpyloric feeding) to restore GI function. Persistence of GI symptoms or worsening of multiple organ dysfunction syndrome and lack of improvement in enteral feeding are classified as AGI grade III (GI failure); this connotes a stage wherein interventions cannot restore GI function. Lastly, presence of acute GI problems that are directly life-threatening is graded as AGI grade IV (GI failure with a severe impact on distant organ function) ${ }^{(3)}$ (Table 1). However, identification of an appropriate method to implement EN in patients with AGI is the key to problems.

\section{Enteral nutrition in the acute phase of critical illness}

Sufficient and appropriate nutrition is essential to sustain the body's metabolism; therefore, malnutrition results in high morbidity and mortality in the ICU setting ${ }^{(32)}$. Some studies have suggested a favourable impact of EEN on outcomes in critically ill patients such as reduced disease severity, lower incidence

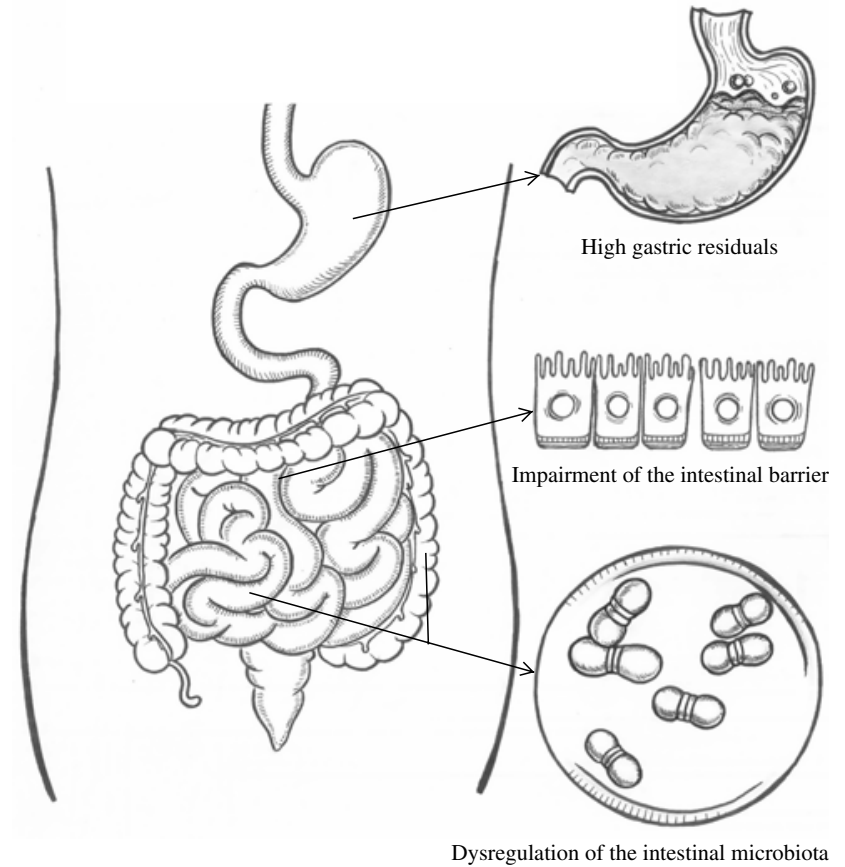

Fig. 1. Acute gastrointestinal injury in critically ill patients. Acute gastrointestinal injury manifests as improper digestion and absorption ${ }^{(3)}$, impairment of the intestinal barrier ${ }^{(28)}$ and dysregulation of the intestinal microbiota ${ }^{(29)}$. Improper digestion and absorption: enteral feeding is impacted whatever the clinical reason (vomiting, high gastric residuals, diarrhoea, gastrointestinal bleeding or presence of entero-cutaneous fistulas) ${ }^{(3)}$. Impairment of the intestinal barrier means increased intestinal permeability ${ }^{(28)}$. Dysregulation of the intestinal microbiota is characterised by low diversity, low abundance of key commensal genera and overgrowth of one bacterial genus. In the figure, high gastric residuals indicate improper digestion and absorption; impairment of the intestinal barrier and dysregulation of the intestinal microbiota are not identified well due to the shortage of evaluation tools ${ }^{(3)}$.

of infectious complications and shorter length of stay in the $\mathrm{ICU}^{(33-35)}$. In contrast, in one randomised controlled trial (RCT), EN within $24 \mathrm{~h}$ of admission in ICU patients was not associated with a reduction in hospital discharge mortality, duration of hospitalisation or ICU length of stay ${ }^{(36)}$; another RCT demonstrated no difference in $30 \mathrm{~d}$ mortality or rates of adverse events in patients who received parenteral nutrition (PN) or EN within $36 \mathrm{~h}$ of an unplanned admission to the $\mathrm{ICU}^{(10)}$. Furthermore, in a single-centre, prospective, controlled clinical trial, aggressive EEN (initiating mechanical ventilation (MV) on day $1 v$. day 5 ) in mechanically ventilated patients was associated with greater infectious complications and prolonged length of hospital stay ${ }^{(37)}$. In another recent study, early isoenergetic EN did not reduce the mortality or the risk of secondary infection in critically ill patients with shock; however, it was associated with an increased risk of digestive complications compared with early isoenergetic $\mathrm{PN}^{(38)}$. However, 2016 Society of Critical Care Medicine (SCCM) and American Society for Parenteral and Enteral Nutrition (ASPEN) guidelines as well as clinical practice guidelines from ESICM recommend the use of EN within 24-48 h in critically ill patients who require nutritional support instead of delaying EN or using early PN because of decreased incidence of infectious complications ${ }^{(7,39)}$, and greater economic benefit and convenience of the $\mathrm{EN}$ route. However, the decrease in 
Table 1. Classification of acute gastrointestinal injury $(A G I)^{(3)}$

\begin{tabular}{|c|c|}
\hline Grade & Definition \\
\hline I & $\begin{array}{l}\text { The function of the Gl tract is partially impaired, expressed as Gl symptoms related to a known cause, and perceived as transient. } \\
\text { Examples: postoperative nausea and/or vomiting during the first days after abdominal surgery, postoperative absence of bowel } \\
\text { sounds, diminished bowel motility in the early phase of shock }\end{array}$ \\
\hline II & $\begin{array}{l}\text { The GI tract is not able to perform digestion and absorption adequately to satisfy the nutrient and fluid requirements of the body. There } \\
\text { are no changes in general condition of the patient related to Gl problems. Examples: gastroparesis with high gastric residuals or } \\
\text { reflux, paralysis of the lower GI tract, diarrhoea, IAH grade I (IAP 12-15 mmHg), visible blood in gastric content or stool. Feeding } \\
\text { intolerance is present if intake of at least } 20 \mathrm{kcal} / \mathrm{kg} \mathrm{BW} \text { per d ( } 84 \mathrm{~kJ} / \mathrm{kg} \mathrm{BW} \text { per d) via enteral route cannot be achieved within } 72 \mathrm{~h} \\
\text { of feeding attempt }\end{array}$ \\
\hline III & $\begin{array}{l}\text { Loss of GI function, and restoration of GI function is not achieved despite interventions, and the general condition is not improving. } \\
\text { Examples: despite treatment, feeding intolerance is persisting - high gastric residuals, persisting Gl paralysis, occurrence or } \\
\text { worsening of bowel dilatation, progression of IAH to grade II (IAP } 15-20 \mathrm{mmHg}) \text {, low APP }(<60 \mathrm{mmHg}) \text {. Feeding intolerance is } \\
\text { present and possibly associated with persistence or worsening of multiple organ dysfunction syndrome }\end{array}$ \\
\hline IV & $\begin{array}{l}\text { AGI has progressed to become directly and immediately life threatening, with worsening of multiple organ dysfunction syndrome and } \\
\text { shock. Examples: bowel ischaemia with necrosis, GI bleeding leading to haemorrhagic shock, Ogilvie's syndrome, ACS requiring } \\
\text { decompression }\end{array}$ \\
\hline
\end{tabular}

GI, gastrointestinal; IAH, intra-abdominal hypertension; IAP, intra-abdominal pressure; BW, body weight; APP, abdominal perfusion pressure; ACS, abdominal compartment syndrome.

infectious complications may be attributable to improvements in current management of vascular access ${ }^{(40)}$, prevention of ventilator-associated pneumonia ${ }^{(41)}$, as well as developments in feeding technology, but not to EN per $s e^{(10,42)}$. Collectively, these findings indicate that there are not enough data to determine the superiority of EEN $v$. delayed EN or to assess the effect of EEN in reducing mortality rates among critically ill patients.

Considerations for implementation of EN other than the timing of initial EN and dose of EN should be important points. One RCT of critically ill patients has shown that permissive underfeeding in the first $7 \mathrm{~d}$ of an ICU stay may be associated with lower hospital mortality rates than that achieved with target feeding ${ }^{(43)}$. Subsequently, a large multicentre RCT was performed to evaluate the effect of 2 weeks of permissive underfeeding (defined as $40-60 \%$ of the calculated energy requirement) $v$, that of standard EN (defined as $70-100 \%$ of the calculated energy requirement) on the mortality of critically ill patients admitted to the ICU within $48 \mathrm{~h}$ after surgery, medical treatment or trauma ${ }^{(44)}$. Protein intake was similar in the two groups, but the permissive underfeeding group received less non-protein energy than the standard EN group ${ }^{(44)}$. The results ${ }^{(43,44)}$ showed that administration of less non-protein energy in the permissive underfeeding group was not associated with lower mortality compared with that associated with administration of a full amount of non-protein energy in the standard EN group; however, blood glucose levels, insulin requirements, need for renal-replacement therapy, and daily fluid balance were lower in the permissive underfeeding group ${ }^{(44)}$. In addition, two RCT of lower energy feeding: initial trophic feeding (defined as 10$20 \mathrm{kcal} / \mathrm{h}(42-84 \mathrm{~kJ} / \mathrm{h})$ or up to $500 \mathrm{kcal} / \mathrm{d}(2090 \mathrm{~kJ} / \mathrm{d})) v$. full EN of approximately $1300 \mathrm{kcal} / \mathrm{d}(5440 \mathrm{~kJ} / \mathrm{d})$ for $6 \mathrm{~d}$ of $\mathrm{MV}$ in patients with acute lung injury (ALI) or acute respiratory failure showed similar clinical outcomes; however, fewer episodes of GI intolerance were observed with initial trophic feeding ${ }^{(11,45)}$. Furthermore, overfeeding of critically ill patients may be associated with hypercapnia, increased risk of infection, metabolic disturbances such as hyperglycaemia, liver dysfunction and extended time on $\mathrm{MV}^{(13,46)}$. In addition, early energy overfeeding was shown to be associated with high mortality in non-septic patients with critical illness ${ }^{(47)}$. Most results showed that restrictive EN (permissive underfeeding in critically ill patient or trophic feeding in patients with ALI) is superior or not inferior to standard EEN or full EEN. These findings suggest that a high dose of EN may cause harm in the acute phase of critical illness.

In the acute phase after a severe insult, aggressive nutritional therapy (for example, by providing exogenous energy support according to energy expenditure) may not have beneficial effects. In fact, this approach is potentially detrimental as it may cause a metabolic overload and/or suppress the ubiquitin-proteasome pathway and the related autophagy pathway, which are potentially important for cellular repair and organ recovery ${ }^{(48,49)}$.

Based on the currently available evidence, early overfeeding may be appropriate in the acute phase of critical illness. Although we think that overuse of the gut may adversely affect the prognosis in the acute phase of critical illness, no studies have compared early trophic feeding with no EN.

\section{Acute gastrointestinal injury and enteral nutrition}

Studies conducted on dogs have shown that enteral nutrients can increase blood flow to the GI tract during the 'postprandial hyperaemic response'. This may preserve gut integrity and prevent gut-derived complications ${ }^{(50,51)}$. Other evidence suggests that trophic effects of EN help maintain intestinal physiology, prevent atrophy of gut villi, reduce intestinal permeability, protect against ischaemia-reperfusion injury by stimulating intestinal perfusion, and preserve gut immunity by affecting gutassociated lymphoid tissue ${ }^{(52)}$.

However, EN may lead to GI complications ${ }^{(53)}$ (vomiting, diarrhoea, GI bleeding, aspiration-related pneumonia, refeeding syndrome, or gut ischaemia) ${ }^{(54)}$. One study found a high frequency of EN-related GI complications in critically ill patients, of which high gastric residuals was the most common; in addition, GI intolerance to EN seemed to prolong the ICU stay and increase mortality ${ }^{(55)}$. Other studies have found an association of early nutrition or EN with increased incidence of ventilator-associated pneumonia in patients with invasive MV and shock $^{(56)}$, and EN resulted in upper digestive intolerance, which 
Table 2. Aggressive or restrictive therapy in critically ill patients*

\begin{tabular}{lll}
\hline Organ or system dysfunction & \multicolumn{1}{c}{ Aggressive therapy } & \multicolumn{1}{c}{ Restrictive therapy } \\
\hline ARDS & Conventional tidal ventilation & Small tidal ventilation \\
& Aggressive fluid management & Restrictive fluid management \\
AKI & Use of diuretics & Restrictive use of diuretics \\
Low Hb & Liberal strategy of erythrocyte transfusion & Restrictive strategy of erythrocyte transfusion \\
AGI & Enough EN & Trophic feeding \\
\hline
\end{tabular}

ARDS, acute respiratory distress syndrome; AKI, acute kidney injury; AGI, acute gastrointestinal injury; EN, enteral nutrition; MV, mechanical ventilation; ALI, acute lung injury. * Using a lower tidal volume with MV can reduce mortality and help reduce the duration of MV compared with use of normal or physiological tidal volume in patients with ARDS/ALI(61). A conservative (as against aggressive) approach to fluid management improves lung function and shortens the duration of MV in patients with ALI ${ }^{(62)}$. A restrictive strategy of erythrocyte transfusion has been shown to be equally effective and potentially superior to a liberal transfusion strategy in critically ill patients ${ }^{(63)}$. Use of diuretics, which causes overuse of residual kidney function, has been shown to be associated with an increased risk of death and non-recovery of renal function in critically ill patients with acute renal failure ${ }^{(64,65)}$

was associated with nosocomial pneumonia, prolonged ICU stay and a high ICU mortality in critically ill patients ${ }^{(57)}$. However, improvement of feeding protocols may help decrease or prevent the complications of $\mathrm{EN}^{(54)}$. However, even if $\mathrm{EN}$ is safe in patients with AGI, identification of patients who are likely to benefit from EN in the acute phase of critical illness is a key imperative.

There is a paucity of studies that have investigated the influence of AGI on the prognosis of critically ill patients who received $\mathrm{EN}$. Therefore, the effect of $\mathrm{EN}$ in critically ill patients with AGI is not well characterised. In addition, there are few guidelines for provision of EN to patients with AGI. The ESICM WGAP recommends initiation of minimal EN $(20 \mathrm{ml} / \mathrm{h})$, the dose of which is actually greater than that of trophic feeding, with subsequent increase in EN to $100 \%$ of the calculated energy requirement in patients with AGI grade I; in patients with AGI grade II or III, it recommends initiation or trial of minimal EN $(20 \mathrm{ml} / \mathrm{h})$ along with other therapy based on the symptoms (for example, prokinetics) (EN is not indicated for patients with AGI grade IV, who typically do not tolerate $\mathrm{EN})^{(3)}$. The aim of trial $\mathrm{EN}$ in the ESICM WGAP recommendations is to improve GI symptoms and to subsequently increase EN to $100 \%$ of the calculated energy requirement ${ }^{(3)}$. The 2016 SCCM/ASPEN guidelines recommend evaluation of GI function and contractility before initiation of $\mathrm{EN}^{(34)}$; however, the guidelines do not address the methodology for evaluation of GI function and the modalities for initiation of EN. In addition, these recommendations $^{(3,39)}$ are not entirely evidence-based, especially with respect to administration of $\mathrm{EN}$ in patients with AGI.

Theoretically, it seems reasonable to suggest that excessive use of an injured GI tract may have deleterious effects. Although there is a paucity of evidence pertaining to the effect of EN in patients with AGI, studies on EEN in patients with acute pancreatitis (AP) ${ }^{(42)}$, which is often associated with AGI, have provided indirect evidence. Although in this multicentre RCT, early nasoenteric tube feeding $(<24 \mathrm{~h})$ was not associated with increased incidence of complications as compared with that with an oral diet after $72 \mathrm{~h}$, it did not reduce the rate of infection or death $^{(42)}$. In another recent RCT, early nasojejunal feeding $(<24 \mathrm{~h})$ in patients with AP did not improve persistent organ failure or mortality compared with no nutritional support ${ }^{(58)}$.

In addition, SCCM/ASPEN guidelines recommend assessment of patients at the time of admission to the ICU for nutrition risk and high nutrition risk (Nutrition Risk Screening 2002 (NRS 2002) $>3$ or Nutrition Risk in the Critically Ill (NUTRIC) score $\geq 5$ ) in order to identify patients who are most likely to benefit from EEN therapy based on expert consensus ${ }^{(39)}$; however, these nutrition risk scores were designed to guide nutrition therapy including $\mathrm{EN}$ and/or $\mathrm{PN}^{(59,60)}$, and high risk scores may be an indication for implementing nutrition therapy, but not necessarily EN. Considering the latest evidence that shows that PN is not inferior to $\mathrm{EN}^{(38)}$, and may serve as a substitute for $\mathrm{EN}$, GI function still should be the main consideration for implementing $\mathrm{EN}$ in patients with both high nutrition risk and AGI.

All in all, EN may increase GI complications which themselves are manifestations of AGI. Although EEN may be safely implemented through improvement of feeding protocols in critically ill patients (even those with AP, which usually manifests as AGI), studies of EEN in patients with AP have shown no indications of its benefit in patients with $\mathrm{AGI}^{(42,58)}$. It is possible that early enteral feeding may not be as effective as we anticipated $^{(42)}$.

\section{Gut rest strategy in critically ill patients}

In critically ill patients with severe injury, therapeutic approaches focus on the pathology (for example, trauma, or necrotic or infected tissue), often allowing survival from a potentially lethal condition. While the adaptive metabolic response to minor trauma is beneficial, an exaggerated metabolic response may cause secondary metabolic damage in patients who survive severe, potentially lethal conditions due to advances in modern medicine ${ }^{(48)}$. Effective treatment must prevent this secondary metabolic damage; however, these interventions must not cause progressive harm. In critical care, evidence suggests that the excessive use of an injured organ is associated with a poor prognosis and restrictive therapy might protect the injured organ from progressive harm, for example, low tidal volume ${ }^{(61)}$ and restrictive fluid management ${ }^{(62)}$ in acute respiratory distress syndrome (ARDS)/ALI, restrictive strategy of erythrocyte transfusion in anaemia $^{(63)}$, and restrictive usage of diuretics in acute renal failure $^{(64,65)}$. Studies conducted on patients with AP did not find a beneficial effect of EEN on prognosis when compared with gut rest $(72 \mathrm{~h})$, which underlines the case for gut rest strategy (Table 2).

Theoretically, 'organ rest' strategy relies on complete rest of the organ, such as lung rest during extracorporeal membrane oxygenation in animal experiments ${ }^{(66)}$. However, in clinical settings, lung rest strategy implies maintaining a small work load, for example, with low inspiratory pressure, low oxygen 
concentration, and moderate positive end expiratory pressure in patients with ARDS/ALI on $\mathrm{MV}^{(67)}$; in other words, this represents a partial lung rest strategy. Similarly, trophic feeding ${ }^{(19)}$ entails a small volume of EN not intended to meet energy requirements but rather to maintain the structural and functional integrity of the GI tract; this may be referred to as a partial gut rest strategy. However, it is necessary to perform more trials to demonstrate the superiority of partial gut rest strategy in critically ill patients with AGI. In addition, comparison of trophic feeding with gut rest strategy should also be performed. Patients with AGI should be enrolled in RCT on EN in future.

The present review might provide a new approach for research on EN in critically ill patients. We propose that delayed trophic feeding (after $72 \mathrm{~h}$ from intensive stress) is the optimal choice for critically ill patients with AGI. As a protective strategy, trophic feeding may reduce the gut burden and help maintain intestinal physiology, sufficient to prevent mucosal atrophy and maintain gut integrity in critically ill patients ${ }^{(39)}$; therefore, it may be applicable to critically ill patients with AGI. To the best of our knowledge, there are no trials that have proven this hypothesis; therefore, large-scale studies are warranted to investigate this approach.

\section{Conclusions}

Injury to the GI tract manifests as improper digestion and absorption, impairment of the intestinal barrier and dysregulation of the intestinal microbiota. EN is believed to improve GI function in critically ill patients. However, we propose that delayed trophic feeding may be the optimal strategy in the acute phase of critical illness considering the adaptive metabolic response and AGI. Trophic feeding may be an organ-protective strategy in critically ill patients, similar to ventilation with a low tidal volume, restrictive fluid resuscitation and restrictive blood transfusion.

\section{Author ORCIDs}

Hongxiang Li (D) 0000-0002-1399-8039

\section{Acknowledgements}

There was no financial support for this study.

D. Z. and Y. L. produced the first draft of the manuscript. L. Q. made the figure. H. L. critically revised the manuscript. All authors saw and approved the final draft of the manuscript.

There are no conflicts of interest.

\section{References}

1. Reintam A, Parm P, Kitus R, et al. (2009) Gastrointestinal symptoms in intensive care patients. Acta Anaesthesiol Scand $\mathbf{5 3}$, 318-324.

2. Piton G, Belon F, Cypriani B, et al. (2013) Enterocyte damage in critically ill patients is associated with shock condition and 28day mortality. Crit Care Med 41, 2169-2176.

3. Reintam Blaser A, Malbrain ML, Starkopf J, et al. (2012) Gastrointestinal function in intensive care patients: terminology, definitions and management. Recommendations of the
ESICM Working Group on Abdominal Problems. Intensive Care Med 38, 384-394.

4. Reintam A, Parm P, Kitus R, et al. (2008) Gastrointestinal failure score in critically ill patients: a prospective observational study. Crit Care 12, R90.

5. Reintam A, Parm P, Redlich U, et al. (2006) Gastrointestinal failure in intensive care: a retrospective clinical study in three different intensive care units in Germany and Estonia. BMC Gastroenterol 6, 19.

6. Li H, Zhang D, Wang Y, et al. (2016) Association between acute gastrointestinal injury grading system and disease severity and prognosis in critically ill patients: a multicenter, prospective, observational study in China. J Crit Care 36, 24-28.

7. Blaser AR, Starkopf J, Alhazzani W, et al. (2017) Early enteral nutrition in critically ill patients: ESICM clinical practice guidelines. Intensive Care Med 43, 380-398.

8. Stahel PF, Flierl MA \& Moore EE (2010) "Metabolic staging" after major trauma - a guide for clinical decision making? Scand $J$ Trauma Resusc Emerg Med 18, 34.

9. Casaer MP, Mesotten D, Hermans G, et al. (2011) Early versus late parenteral nutrition in critically ill adults. New Engl J Med 365, 506-517.

10. Harvey SE, Parrott F, Harrison DA, et al. (2014) Trial of the route of early nutritional support in critically ill adults. New EnglJMed 371, 1673-1684.

11. National Heart, Lung, and Blood Institute Acute Respiratory Distress Syndrome (ARDS) (2012) Initial trophic vs full enteral feeding in patients with acute lung injury: the EDEN randomized trial. JAMA 307, 795-803.

12. Stratakis CA \& Chrousos GP (2010) Neuroendocrinology and pathophysiology of the stress system. Ann $N$ Y Acad Sci 771, 1-18.

13. Preiser JC, van Zanten AR, Berger MM, et al. (2015) Metabolic and nutritional support of critically ill patients: consensus and controversies. Crit Care 19, 35.

14. Lena D, Kalfon P, Preiser JC, et al. (2011) Glycemic control in the intensive care unit and during the postoperative period. Anesthesiology 114, 438-444.

15. Preiser JC, Ichai C, Orban JC, et al. (2014) Metabolic response to the stress of critical illness. Br J Anaesth 113, 945-954.

16. Gué M, Peeters T, Depoortere I, et al. (1989) Stress-induced changes in gastric emptying, postprandial motility, and plasma gut hormone levels in dogs. Gastroenterology 97, 1101-1107.

17. Chrousos GP (2009) Stress and disorders of the stress system. Nat Rev Endocrinol 5, 374-381.

18. Richardson RS, Norton LW, Sales JE, et al. (1973) Gastric blood flow in endotoxin-induced stress ulcer. Arch Surg 106, 191-195.

19. Wallon C, Yang PC, Keita $\AA$ V, et al. (2008) Corticotropinreleasing hormone (CRH) regulates macromolecular permeability via mast cells in normal human colonic biopsies in vitro. Gut 57, 50-58.

20. Konturek PC, Brzozowski T \& Konturek SJ (2011) Stress and the gut: pathophysiology, clinical consequences, diagnostic approach and treatment options. J Physiol Pharmacol 62, 591-599.

21. Halter JB, Pflug AE \& Porte Jr D (1977) Mechanism of plasma catecholamine increases during surgical stress in man. J Clin Endocrinol Metab 45, 936-944.

22. Krejci V, Hiltebrand LB \& Sigurdsson GH (2006) Effects of epinephrine, norepinephrine, and phenylephrine on microcirculatory blood flow in the gastrointestinal tract in sepsis. Crit Care Med 34, 1456-1463.

23. Chapman M, Fraser R, Vozzo R, et al. (2005) Antro-pyloro-duodenal motor responses to gastric and duodenal nutrient in critically ill patients. Gut 54, 1384-1390. 
24. Hinshaw LB (1996) Sepsis/septic shock: participation of the microcirculation: an abbreviated review. Crit Care Med $\mathbf{2 4}$, 1072-1078.

25. Chung DH, Evers BM, Townsend CM, et al. (1992) Burninduced transcriptional regulation of small intestinal ornithine decarboxylase. Am J Surg 163, 157-163.

26. Lee WL \& Slutsky AS (2010) Sepsis and endothelial permeability. N Engl J Med 363, 689-691.

27. Verburgh P, Reintam-Blaser A, Kirkpatrick AW, et al. (2014) Overview of the recent definitions and terminology for acute gastrointestinal injury, intra-abdominal hypertension and the abdominal compartment syndrome. Reanimation 23, Suppl. 2, 379-393.

28. Li H, Chen Y, Huo F, et al. (2017) Association between acute gastrointestinal injury and biomarkers of intestinal barrier function in critically ill patients. BMC Gastroenterol 17, 45.

29. Lankelma JM, van Vught LA, Belzer C, et al. (2016) Critically ill patients demonstrate large interpersonal variation in intestinal microbiota dysregulation: a pilot study. Intensive Care Med $\mathbf{4 3}$, 59-68.

30. Burgstad CM, Besanko LK, Deane AM, et al. (2013) Sucrose malabsorption and impaired mucosal integrity in enterally fed critically ill patients: a prospective cohort observational study. Crit Care Med 41, 1221-1228.

31. Jacobs MC, Haak BW, Hugenholtz F, et al. (2017) Gut microbiota and host defense in critical illness. Curr Opin Crit Care 23, 257-263.

32. Giner M, Laviano A, Meguid MM, et al. (1996) In 1995 a correlation between malnutrition and poor outcome in critically ill patients still exists. Nutrition 12, 23-29.

33. Heyland DK, Stephens KE, Day AG, et al. (2011) The success of enteral nutrition and ICU-acquired infections: a multicenter observational study. Clin Nutr 30, 148-155.

34. Heidegger CP, Berger MM, Graf S, et al. (2013) Optimisation of energy provision with supplemental parenteral nutrition in critically ill patients: a randomised controlled clinical trial. Lancet 381, 385-393.

35. Khalid I, Doshi P \& Digiovine B (2010) Early enteral nutrition and outcomes of critically ill patients treated with vasopressors and mechanical ventilation. Am J Crit Care 19, 261-268.

36. Doig GS, Simpson F, Finfer S, et al. (2008) Effect of evidencebased feeding guidelines on mortality of critically ill adults: a cluster randomized controlled trial. JAMA 300, 2731-2741.

37. Ibrahim E, Mehringer L, Prentice D, et al. (2002) Early versus late enteral feeding of mechanically ventilated patients: results of a clinical trial. J Parenter Enteral Nutr 26, 174-181.

38. Reignier J, Boisramé-Helms J, Brisard L, et al. (2018) Enteral versus parenteral early nutrition in ventilated adults with shock: a randomised, controlled, multicentre, open-label, parallelgroup study (NUTRIREA-2). Lancet 391, 133-143.

39. McClave S, Taylor B \& Martindale R (2016) Guidelines for the provision and assessment of nutrition support therapy in the adult critically ill patient: Society of Critical Care Medicine (SCCM) and American Society for Parenteral and Enteral Nutrition (A.S.P.E.N.). J Parenter Enteral Nutr 40, 159-211.

40. Bion J, Richardson A, Hibbert P, et al. (2013) 'Matching Michigan': a 2-year stepped interventional programme to minimise central venous catheter-blood stream infections in intensive care units in England. BMJ Qual Saf 22, 110-123.

41. Li Bassi G, Senussi T \& Aguilera Xiol E (2017) Prevention of ventilator-associated pneumonia. Curr Opin Infect Dis 30, 214-220.

42. Bakker OJ, van Brunschot S, van Santvoort HC, et al. (2014) Early versus on-demand nasoenteric tube feeding in acute pancreatitis. N Engl J Med 371, 1983-1993.
43. Arabi YM, Tamim HM, Dhar GS, et al. (2011) Permissive underfeeding and intensive insulin therapy in critically ill patients: a randomized controlled trial. Am J Clin Nutr 93, 569-577.

44. Arabi YM, Aldawood AS, Haddad SH, et al. (2015) Permissive underfeeding or standard enteral feeding in critically ill adults. N Engl J Med 372, 2398-2408.

45. Rice TW, Mogan S, Hays MA, et al. (2011) Randomized trial of initial trophic versus full-energy enteral nutrition in mechanically ventilated patients with acute respiratory failure. Crit Care Med 39, 967-974.

46. Klein CJ, Stanek GS \& Wiles CE III (1998) Overfeeding macronutrients to critically ill adults: metabolic complications. $J \mathrm{Am}$ Diet Assoc 98, 795-806.

47. Weijs PJ, Looijaard WG, Beishuizen A, et al. (2014) Early high protein intake is associated with low mortality and energy overfeeding with high mortality in non-septic mechanically ventilated critically ill patients. Crit Care 18, 701.

48. Hartl WH \& Jauch KW (2014) Metabolic self-destruction in critically ill patients: origins, mechanisms and therapeutic principles. Nutrition 30, 261-267.

49. Schetz M, Casaer MP \& Van den Berghe G (2013) Does artificial nutrition improve outcome of critical illness? Crit Care 17, 302.

50. Kazamias P, Kotzampassi K, Koufogiannis D, et al. (1998) Influence of enteral nutrition-induced splanchnic hyperemia on the septic origin of splanchnic ischemia. World J Surg 22 , 6-11.

51. Purcell PN, Davis K Jr, Branson RD, et al. (1993) Continuous duodenal feeding restores gut blood flow and increases gut oxygen utilization during PEEP ventilation for lung injury. Am J Surg 165, 188-193.

52. Schmidt $H \&$ Martindale R (2001) The gastrointestinal tract in critical illness. Curr Opin Clin Nutr 4, 547-551.

53. Hsu CW, Sun SF, Lin SL, et al. (2009) Duodenal versus gastric feeding in medical intensive care unit patients: a prospective, randomized, clinical study. Crit Care Med 37, 1866-1872.

54. Boullata JI, Carrera AL, Harvey L, et al. (2017) ASPEN Safe Practices for Enteral Nutrition Therapy. JPEN J Parenter Enteral Nutr 41, 15-103.

55. Montejo JC (1999) Enteral nutrition-related gastrointestinal complications in critically ill patients: a multicenter study. The Nutritional and Metabolic Working Group of the Spanish Society of Intensive Care Medicine and Coronary Units. Crit Care Med 27, 1447-1453.

56. Reignier J, Darmon M, Sonneville R, et al. (2015) Impact of early nutrition and feeding route on outcomes of mechanically ventilated patients with shock: a post hoc marginal structural model study. Intensive Care Med 41, 875-886.

57. Mentec H, Dupont H, Bocchetti M, et al. (2001) Upper digestive intolerance during enteral nutrition in critically ill patients: frequency, risk factors, and complications. Crit Care Med 29, 1955-1961.

58. Stimac D, Poropat G, Hauser G, et al. (2016) Early nasojejunal tube feeding versus nil-by-mouth in acute pancreatitis: a randomized clinical trial. Pancreatology 16, 523-528.

59. Heyland DK, Dhaliwal R, Jiang X, et al. (2011) Identifying critically ill patients who benefit the most from nutrition therapy: the development and initial validation of a novel risk assessment tool. Crit Care 15, R268.

60. Jie B, Jiang ZM, Nolan MT, et al. (2012) Impact of preoperative nutritional support on clinical outcome in abdominal surgical patients at nutritional risk. Nutrition 28, 1022-1027.

61. Ney L \& Kuebler WM (2000) Ventilation with lower tidal volumes as compared with traditional tidal volumes for acute lung injury. $N$ Engl J Med 343, 813-814.

62. National Heart, Lung, and Blood Institute Acute Respiratory Distress Syndrome (ARDS) Clinical Trials Network, 
Wiedemann HP, Wheeler AP, et al. (2006) Comparison of two fluid-management strategies in acute lung injury. $N$ Engl J Med 354, 2564-2575.

63. Hébert PC, Wells G, Blajchman MA, et al. (1999) A multicenter, randomized, controlled clinical trial of transfusion requirements in critical care. $N$ Engl J Med 340, 409-417.

64. Mehta RL, Pascual MT, Soroko S, et al. (2002) Diuretics, mortality, and nonrecovery of renal function in acute renal failure. JAMA 288, 2547-2553.

65. Bagshaw SM, Gibney RTN, Kruger P, et al. (2017) The effect of low-dose furosemide in critically ill patients with early acute kidney injury: a pilot randomized blinded controlled trial (the SPARK study). J Crit Care 42, 138-146.

66. Frattallone JM, Fuhrman BP, Kochanek PM, et al. (1988) Management of pulmonary barotrauma by extracorporeal membrane oxygenation, apnea, and lung rest. J Pediatr 112, 787-789.

67. Peek GJ, Mugford M, Tiruvoipati R, et al. (2009) Efficacy and economic assessment of conventional ventilatory support versus extracorporeal membrane oxygenation for severe adult respiratory failure (CESAR): a multicentre randomised controlled trial. Lancet 374, 1351-1363. 